\title{
Radiotherapy for ocular angiomas
}

Although rare, choroidal angiomas generate a disproportionate amount of interest within the profession as they cause visual loss, frequently severe, in otherwise healthy people. They are more readily diagnosed than 20 years ago as a result of modern ultrasonography and fluorescein angiography. These benign, sight threatening tumours cause visual loss by leakage of subretinal fluid. ${ }^{1}$ Symptomatic presentation occurs earlier when the haemangioma is located close to the posterior pole and within the macular arcades. Diffuse haemangiomas are usually associated with involvement of other ocular structures and with the encephalofacial angiomas as part of the Sturge-Weber syndrome; these may even be bilateral. They are congenital abnormalities, but leakage may not occur until late in the first or second decade. All ocular haemangiomas may remain occult and asymptomatic for long periods and circumscribed angiomas (which are only rarely associated with systemic abnormalities) often only present in the fourth to fifth decades. Leakage may be intermittent at first, but is later sustained.

In diffuse haemangioma of the Sturge-Weber type, ultrasound reveals that the whole choroid is slightly thickened. Leakage seems associated with the development of a localised, circumscribed choroidal nodule. Circumscribed angiomas are always unilateral and the involved area of choroid is, as the name implies, confined. There is a third group of patients who have no apparent encephalofacial involvement and who present relatively early in the second to third decades with apparently circumscribed haemangioma and yet, on ultrasound, there is diffuse choroidal thickening. Although Witschel and Font described differing histological features of ostensibly circumscribed versus diffuse angiomas, ${ }^{2}$ these ultrasound findings suggest that there is a spectrum of disease; leakage probably occurs when nodular thickening of a critical size develops.

Once symptoms develop, visual deterioration will continue and treatment is indicated. The course of this visual deterioration is often slow and faltering, with periods of remission, such that a false sense of security fuels clinician inertia until serious visual loss occurs (when the best chance of a good visual result after treatment is lost). Ultimately, central vision is lost because of cystoid macular oedema; this frequently occurs within a few years of the onset of symptoms.

Surface grid photocoagulation has become an established treatment for circumscribed haemangiomas. Although photocoagulation of circumscribed choroidal haemangiomas results in temporary resolution of subretinal fluid, subsequent recurrence of this is common. Several reports have documented the reaccumulation of subretinal fluid in patients treated by laser, and their poor final visual acuity. ${ }^{1{ }^{34}}$ As retinal detachment is usually more extensive in the diffuse choroidal haemangiomas, treatment by laser may require initial drainage of the subretinal fluid; this treatment plan has met with only limited success. ${ }^{5}$

The use of radiotherapy, both brachtherapy ${ }^{6} 7$ and external beam technology, ${ }^{8-10}$ in the treatment of ocular angioma is not new, nor is the appreciation that these largely cavernous angiomas are more radiosensitive than the retinal capillary angiomas of Von Hippel-Lindau syndrome. The recent impetus to use external beam radiotherapy has undoubtedly been fired by more sophisticated technology, allowing the lens and anterior segment to be spared. $^{11-13}$
Currently, two groups are reporting good effects of radiotherapy in this disease (Schilling et al, in this issue of the $B \mathcal{O} O$, p 267 and Madreperla et $\mathrm{al}^{14}$ ) and these benefits of radiotherapy seem to be better sustained than those of photocoagulation. In the larger external beam series reported on p 267, the Essen/Berlin workers describe good results in terms of resolution of subretinal fluid and improved visual acuity for the majority of patients with both circumscribed and diffuse angiomas. The effect on improvement of vision was inversely related to the lag time (after onset of symptoms to the time of referral). In a small minority of patients, initial visual improvement was followed by later deterioration, attributed to subretinal fibrosis that extended to the macula (a point that must be borne in mind if higher radiation doses are to be advocated, see below) and secondary glaucoma accounted for other therapeutic failures.

In the Barts/Moorfields patients, Madreperla et al report a similar but smaller external beam series but compare it with parallel series of patients treated with radiation brachytherapy and photocoagulation. ${ }^{14}$ The low dose external beam radiotherapy results are similar to those of the German group-complete resolution of subretinal fluid and retinal detachment in 5/5 diffuse angioma cases, with visual improvement in $2 / 5$ cases and stabilisation in the other three cases. The radiation plaque brachytherapy data are of interest in that $8 / 8$ patients achieved resolution of fluid sustained for at least 1 year and no recurrence in the series to date (with four cases followed beyond 4 years). Visual improvement paralleled this resolution of fluid. (Ophthalmologists not familiar with radiotherapy should note that brachytherapy, in general, delivers higher radiation dose equivalents than the external beam dosages under discussion here.) Both the external beam and brachytherapy data compared favourably with the photocoagulation data in terms of durability of effect on fluid accumulation and visual improvement; the tumours flattened with more certainty after brachytherapy. The authors concluded that radiotherapy is indicated as primary therapy and that the results of brachytherapy for circumscribed haemangiomas and the external beam data for diffuse Sturge-Weber type haemangiomas are particularly encouraging. A point of note here is that following external beam therapy to the relatively low dose equivalents cited by both groups the thickness of the angiomas is frequently unchanged on follow up scans and, in patients with subfoveal or parafoveal tumours, visual distortion may replace blurring when the retina settles back onto the elevated tumour. By contrast, the patients treated with higher dose equivalent brachytherapy have flattened tumours following treatment and this distortion phenomenon seems less of a problem. Zografos and colleagues also remain advocates of brachytherapy, ${ }^{15}$ although the optimal radiation dose remains controversial; a similar question mark hangs over those few data that are available on proton beam therapy. The London group are now considering increasing their external beam dosage in cases where visual distortion is anticipated. Where there is total retinal detachment, radiotherapy will not restore vision but may allow preservation of the eye by preventing neovascular glaucoma.

The similarities and differences between the German and London groups are worthy of comment. Both groups agree that radiotherapy is the most effective primary treatment and that early treatment of symptomatic patients is to 
be advocated. The German group is content with low dose external beam radiotherapy and believes that higher dose brachytherapy has little place in management. The London group will continue to advocate brachytherapy and cautiously derived higher dose external beam radiotherapy prescriptions in the clinical situations that they have found most beneficial. Which group proves correct on this matter demands lengthy follow up of visual progress over $10+$ years and it is hoped that both teams will continue their analyses for this length of time.

The conclusions are encouraging ones-namely, that modern radiotherapy allows better treatment of symptomatic ocular angiomas than previous methods, including sustained visual improvement, and that this facility is now routinely available to patients. Clinical ophthalmologists should be aware of these results, particularly as early referral will save vision.

St Bartholomew's, Moorfields, and

P N PLOWMAN Great Ormond St Children's Hospitals, London

1 Augsberger JJ, Shields JA, Moffat KP. Circumscribed choroidal hemangiomas: long-term visual prognosis. Retina 1981;1:56-61.
2 Witschel H, Font RL. Hemangioma of the choroid. A clinicopathological study of 71 cases and a review of the literature. Surv Opthalmol 1976;20:415-31

3 Sanborn GE, Augsberger JJ, Shields JA. Treatment of circumscribed choroidal hemangiomas. Am f Ophthalmol 1982;89:1374-80.

4 Anand R, Augsberger JJ, Shields JA. Circumscribed choroidal hemangiomas. Arch Ophthalmol 1989;107:1338-42.

5 Shields JS, Shields CL. Intra-ocular tumours: $a$ text and an atlas. Philadelphia: W B Saunders, 1992 Chapter 13.

6 MacLean AL, Maumenee AE. Hemangima of the choroid. Am f Ophthalmol 1960;50:3-11.

7 Zografos L, Gailloud C, Bercher L. Irradiation treatment of choroidal hemangiomas. H Francais d'Ophtalmol 1989;12:797-807.

8 Alberti W, Greber H, John V, Wessing A, Scherer E. Radiotherapy of the hemangioma of the choroid (German). Strahlentherapie 1983;159:160-7.

9 Plowman PN, Harnett AN. Radiotherapy in benign orbital disease 1. Complicated ocular angiomas. Br f Ophthalmol 1988;72:266-88.

10 Greber H, Wessing A, Alberti W, Scherer E. Successful treatment of choroidal hemangioma with secondary changes caused by Sturge Weber syndrome. Klin Monatsbl Augenheilkd 1984;185:276-8.

11 Schipper J. An accurate and simple method for megavoltage irradiation of retinoblastoma. Radiother Oncol 1983;1:31-41.

12 Harnett AN, Hungerford JL, Lambert GD, Hirst A, Darlison R, Hart BL, et al. Improved external beam radiotherapy for the treatment of retinoblastoma. Br f Radiol 1987;60:753-60.

13 Plowman PN. Radiotherapy and ophthalmology, time for a friendly re-acquaintance. Br f Ophthalmol 1992;76:307-9.

14 Madreperla SA, Hungerford JL, Plowman PN. Choroidal haemangiomas: treatment by photocoagulation or radiotherapy. Ophthalmology (in press).

15 Zografos L, Bercher L, Chamot L, Gailloud C, Raimondi S, Egger E. Cobalt-60 treatment of choroidal hemangiomas. Am $\mathcal{f}$ Ophthalmol 1996;121:190-9. 